\title{
Ion irradiation-induced swelling and hardening effect of Hastelloy
} $\mathrm{N}$ alloy

\author{
S.J. Zhang ${ }^{\text {a,b }}$, D.H. Li ${ }^{\text {b }}$, H.C. Chen ${ }^{\text {b }}$, G.H. Lei ${ }^{\text {b }}$, H.F. Huang ${ }^{\text {b }}$, W. Zhang ${ }^{\text {, }}$, C.B. Wang ${ }^{\text {, }}$, L. \\ Yan $^{\text {b,*, D.J. Fu }}{ }^{\text {a }}$, M. Tang ${ }^{c}$ \\ ${ }^{a}$ Key Laboratory of Artificial Micro-and Nano-structures of Ministry of Education, School of Physics \\ and Technology, Wuhan University, Wuhan 430072, China \\ ${ }^{\mathrm{b}}$ Shanghai Institute of Applied Physics, Chinese Academy of Sciences, Shanghai 201800, China \\ ${ }^{\mathrm{c}}$ Los Alamos National Laboratory, Los Alamos, NM 87545, USA
}

\begin{abstract}
The volumetric swelling and hardening effect of irradiated Hastelloy $\mathrm{N}$ alloy were investigated in this paper. $7 \mathrm{MeV}$ and $1 \mathrm{MeV} \mathrm{Xe}$ ions irradiations were performed at room temperature (RT) with irradiation dose ranging from 0.5 to $27 \mathrm{dpa}$. The volumetric swelling increases with increasing irradiation dose, and reaches up to $3.2 \%$ at $27 \mathrm{dpa}$. And the irradiation induced lattice expansion is also observed. The irradiation induced hardening initiates at low ion dose $(\leq 1 \mathrm{dpa})$ then saturates with higher ion dose. The irradiation induced volumetric swelling may be ascribed to excess atomic volume of defects. The irradiation induced hardening may be explained by the pinning effect where the defects can act as obstacles for the free movement of dislocation lines. And the evolution of the defects' size and number density could be responsible for the saturation of hardness.
\end{abstract}

\section{Introduction}

Molten salt reactor (MSR), one of the generation IV nuclear reactor systems, has received worldwide attention for its high safety, reliability and high efficiency [1]. The structural materials in MSR are confronted with the challenge of the extreme harsh environments, such as high temperature, strong corrosive molten salt and high fluence of neutron irradiation [2]. Hastelloy $\mathrm{N}$ alloy has been considered as one of promising structural materials for MSR application thanks to its good 
high-temperature mechanical strength and compatibility with fluoride salts $[1,3]$. However, swelling and embrittlement were the primary irradiation degradation pathways in nickel-based alloys [4]. Hence, the performance of Hastelloy $\mathrm{N}$ alloy under radiation is of particular importance for ensuring the safe operation of MSR.

In the 1970's, some neutron irradiation studies on mechanical properties of Hastelloy $\mathrm{N}$ alloy were carried out under the framework of Molten Salt Reactor Experiment (MSRE) program [1]. However, detail radiation damage study of Hastelloy $\mathrm{N}$ alloy was rarely reported. In recent years, the high dose, high flux ion irradiations have been considered as a useful tool to understand the basic mechanisms of irradiation damage in structural materials, especially for the evolution of the irradiation induced microstructures and properties [5-10]. M. Liu et al. investigated the microstructural evolution of Hastelloy $\mathrm{N}$ alloy using $\mathrm{Ar}$ ion irradiation and observed that the black dot defects and small dislocation loops emerged at dose of 0.4 and 4 dpa respectively, and the size of those loops increased with irradiation fluence [11]. K. Liu et al. reported that the size and the density of defects produced at a low irradiation dose rate were larger and higher than that at a high irradiation dose rate [12]. In addition, for $3 \mathrm{MeV} \mathrm{Au}$ ions irradiated Hastelloy $\mathrm{N}$ alloy, the volumetric swelling of $1.3 \%$ and $6.6 \%$ were observed with irradiation doses of 30 and $58 \mathrm{dpa}$, respectively $[13,14]$. However, the irradiation-induced volumetric swelling and hardening of Hastelloy $\mathrm{N}$ alloy, the important issues of irradiation damage, still lack detailed data and systematic analysis.

The focus of this study is, the irradiation-induced volumetric swelling and hardening of Hastelloy $\mathrm{N}$ alloy under heavy ion irradiations. Radiation-induced microstructural evolution was characterized using Atomic Force Microscope (AFM), Grazing Incident X-Ray Diffraction (GIXRD) and Transmission Electron Microscope (TEM). Additionally, the Nanoindenter was used to measure the irradiation induced hardening. The relationship between ion irradiation induced microstructural evolution and hardening was also discussed in this study. 


\section{Experimental}

\subsection{Materials and irradiation conditions}

Hastelloy $\mathrm{N}$ alloy in this study was obtained from Haynes International, Inc. Table 1 shows the nominal chemical composition of this alloy. The bulk materials were cut into $10 \mathrm{~mm} \times 10 \mathrm{~mm} \times 1 \mathrm{~mm}$ and polished with $\mathrm{SiC}$ sandpapers at the grade of 400 - 2000, vibration polishing (including nano alumina powder $\sim 20 \mathrm{~nm}$ ) to obtain a smooth surface, followed by the ultrasonic cleaning in acetone and deionized water.

Table 1 the nominal chemical composition of Hastelloy $\mathrm{N}$ alloy

\begin{tabular}{lllllllllll}
\hline Elements & $\mathrm{C}$ & $\mathrm{Co}$ & $\mathrm{Cu}$ & $\mathrm{Al}$ & $\mathrm{Si}$ & $\mathrm{Mn}$ & $\mathrm{Fe}$ & $\mathrm{Cr}$ & $\mathrm{Mo}$ & $\mathrm{Ni}$ \\
\hline Wt.\% & 0.06 & $<0.1$ & 0.06 & 0.15 & 0.27 & 0.51 & 4.24 & 6.96 & 17 & $\mathrm{Bal}$ \\
\hline
\end{tabular}

The ion irradiation experiments were performed on the terminal of $320 \mathrm{kV}$ High-Voltage Experimental platform equipped with an electron cyclotron resonance ion source in Institute of Modern Physics, Chinese Academy of Sciences (IMP-CAS) [15]. The incident ion flux was kept in a low level $\left(\sim 1.2 \times 10^{11} \mathrm{ions} / \mathrm{cm}^{2} \cdot \mathrm{s}\right)$ to avoid significant temperature increase in the samples during irradiation. The as-prepared bulk samples were irradiated by $7 \mathrm{MeV} \mathrm{Xe}^{26+}$ ions at room temperature (RT) with the ion fluence of $2 \times 10^{14}, 4 \times 10^{14}, 2.4 \times 10^{15}$ and $4 \times 10^{15} \mathrm{~cm}^{-2}$, corresponding to the peak doses of $0.5,1,6$ and 10 dpa. Additionally, in order to get the higher ion dose, one prepared bulk sample was also irradiated with $1 \mathrm{MeV} \mathrm{Xe}^{20+}$ ions, where the ion fluence reached $6.6 \times 10^{15} \mathrm{~cm}^{-2}(27 \mathrm{dpa})$. In this study, part of the surface regions for each sample was blocked from ion beam during the ion irradiation experiments to allow the characterization of irradiation induced swelling. 


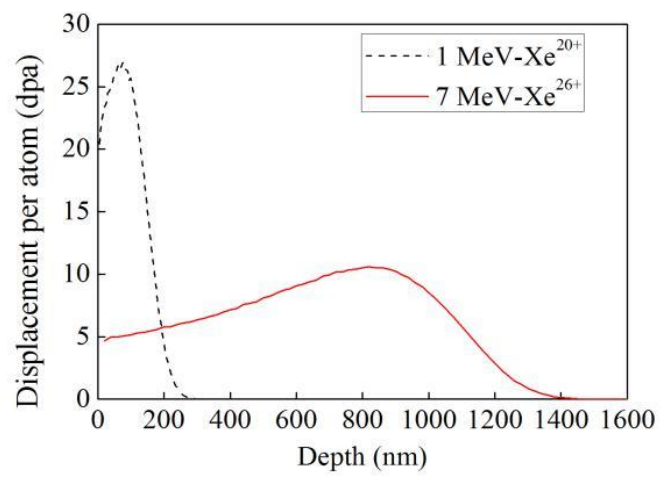

Fig. 1. SRIM calculation of the damage profile produced by $1 \mathrm{MeV}$ and $7 \mathrm{MeV} \mathrm{Xe}$ ions with fluence of $6.6 \times 10^{15} \mathrm{~cm}^{-2}$ and $4 \times 10^{15} \mathrm{~cm}^{-2}$ respectively in Hastelloy $\mathrm{N}$ alloy.

Fig. 1 shows the damage profile with different ions irradiations calculated with "K-P quick calculation" mode using SRIM-2013 software [16], wherein the threshold displacement energy $E_{d}$ was set to $40 \mathrm{eV}$ [17]. The irradiated damage depth caused by $1 \mathrm{MeV}$ and $7 \mathrm{MeV}$ Xe ions are approximately $300 \mathrm{~nm}$ and $1400 \mathrm{~nm}$, respectively.

\subsection{Characterization methods}

The surface morphologies and the boundaries between the unirradiated and irradiated regions were characterized by atomic force microscope (AFM). Nanoindentation measurements for $7 \mathrm{MeV}$ Xe ions irradiated samples were performed using G200 nanoindenter in the continuous stiffness mode [18]. The indentation depth was kept at $1400 \mathrm{~nm}$ which corresponds to the irradiation damage depth, and 30 single indents were measured for each sample. The lattice structures of unirradiated and irradiated samples were determined by grazing incident X-ray diffraction (GIXRD) using a $\mathrm{Cu} \mathrm{K}$ al irradiation source (the wavelength $\lambda=0.15418 \mathrm{~nm}$ ). On basis of the damage depths mentioned above, the grazing incident angles $(\theta)$ were set to $1^{\circ}$ and $4^{\circ}$ for the samples irradiated by $1 \mathrm{MeV}$ and $7 \mathrm{MeV} \mathrm{Xe}$ ions, respectively. The cross sectional TEM samples were prepared using a Zeiss Auriga 60 Focus Ion Beam (FIB). A Tecnai G2 F20 transmission electron microscope (TEM) with the accelerating voltage of $200 \mathrm{kV}$ was used to characterize the microstructural evolution of irradiated samples. 


\section{Results}

\subsection{The irradiation induced volumetric swelling}

Fig. 2(a) shows the typical AFM image of the topography near the boundary between the irradiated and unirradiated region of the sample irradiated with $7 \mathrm{MeV}$ Xe at a dose of $10 \mathrm{dpa}$. The step heights at five different areas of this sample were measured and three tests at one area were collected as shown Fig. 2(b). The irradiated region of the sample was raised significantly above the unirradiated region, indicating the volumetric swelling occurred. The average step heights were $0 \mathrm{~nm}, 20.0 \mathrm{~nm}, 28.2$ $\mathrm{nm}$ and $13.0 \mathrm{~nm}$, corresponding to the samples irradiated with irradiation dose of 1,6 , $10 \mathrm{dpa}(7 \mathrm{MeV} \mathrm{Xe})$ and $27 \mathrm{dpa}(1 \mathrm{MeV} \mathrm{Xe})$, respectively. The step height measurements provide the total integrated swelling along the entire range modified by the irradiated ions. The volumetric swelling percentage is calculated based on the step height divided by the nominal damage range. Here, the damage depth for $7 \mathrm{MeV}$ and $1 \mathrm{MeV} \mathrm{Xe}$ ions are $1600 \mathrm{~nm}$ and $400 \mathrm{~nm}$ respectively, which are based on both simulations using the SRIM code and TEM observation. Thus, the swelling percentage for the irradiated samples at 1, 6, 10 and $27 \mathrm{dpa}$ are $0,1.2 \%, 1.7 \%$ and $3.2 \%$, respectively, as shown in the red squares in Fig. 2(c). The volumetric swelling of irradiated Hastelloy $\mathrm{N}$ increases as a function of irradiation dose and no saturation is observed at this range of ion dose.

It should be noted that P. Guo et al. [13] and S.Y. Liu et al. [14] used $3 \mathrm{MeV} \mathrm{Au}$ ions to irradiate Hastelloy $\mathrm{N}$ at $\mathrm{RT}$ with irradiation doses of 30 and 58 dpa respectively, and the swelling percentage still increases at the irradiation dose of 58 dpa, as shown with the blue triangles in Fig. 2(c). The irradiation induced swelling effect on pure nickel was also reported by K. Jin et al. [19], as shown with the black circles in Fig. 2(c). The swelling percentage of pure nickel irradiated by $3 \mathrm{MeV} \mathrm{Ni}^{2+}$ ions at $500{ }^{\circ} \mathrm{C}$ are $0.2 \%, 1.8 \%, 3.7 \%$ and $6.7 \%$ at the irradiation dose of $1,5.3,16$ and 53 dpa, respectively. It can be seen that the volumetric swelling of irradiated Hastelloy $\mathrm{N}$ is lower than irradiated pure nickel, namely, Hastelloy $\mathrm{N}$ may show better 
resistance to irradiation-induced swelling than pure nickel.
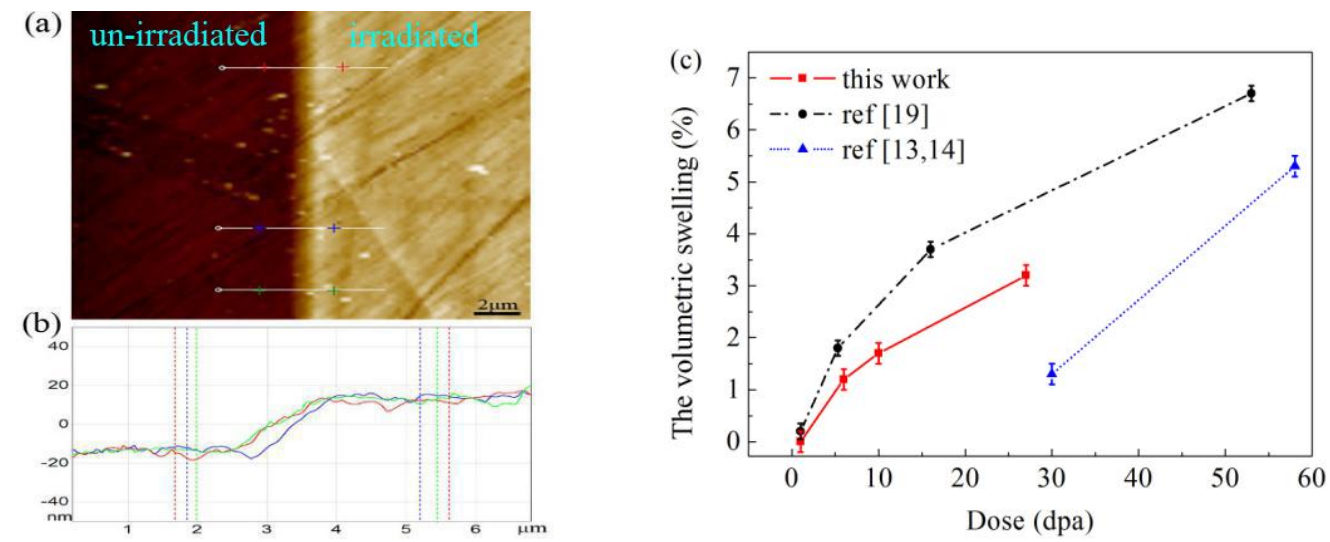

Fig. 2. (a) AFM image of the irradiated and unirradiated region of the sample at $10 \mathrm{dpa}$ (7 $\mathrm{MeV} \mathrm{Xe),(b)} \mathrm{the} \mathrm{measured} \mathrm{step} \mathrm{heights} \mathrm{in} \mathrm{(a),} \mathrm{(c)} \mathrm{the} \mathrm{swelling} \mathrm{percentage} \mathrm{of} \mathrm{irradiated} \mathrm{samples} \mathrm{as}$ a function of the ion dose: the red squares shows this work, the blue triangles show the swelling data about Hastelloy $\mathrm{N}$ from reference [13,14], the black circles show the swelling data about pure nickel from reference [19].

\subsection{Nanoindentation hardness}

Nanoindentation was performed on pristine and irradiated samples using a G200 Nanoindenter system with a Berkovich-type indentation tip. The indentation depth was kept at $1400 \mathrm{~nm}$ which corresponds with the irradiation damage depth, 30 single indents were measured for each sample. When the indented depth was less than $50 \mathrm{~nm}$, the measured hardness values were not accurate because of the uncertainty in the indenter tip geometry, strain rate effects around the tip, and other surface artifacts such as surface contamination films [20].

The average nanoindentation hardness values of Hastelloy $\mathrm{N}$ before and after $\mathrm{Xe}$ ions irradiation have been plotted as a function of indentation depth, as shown in Fig. 3(a). For the unirradiated sample, the hardness decreases slightly with indentation depth, as shown with the black curve in Fig. 3(a), This could be explained with a model developed by Nix and Gao based on the concept of geometrically necessary dislocation [21]. Which predicts the hardness-depth profile as follows:

$$
H=H_{0} \sqrt{1+h^{*} / h}
$$


Where $H_{0}$ is the hardness in the limit of infinite depth and $h^{*}$ is a characteristic length that depends on the material and the shape of the indenter. Here, $h^{*}$ can be considered as a constant for a given material and indenter. It is clear that as the indentation depth (h) increases, the measured hardness value decreases gradually and finally approaches $H_{0}$.
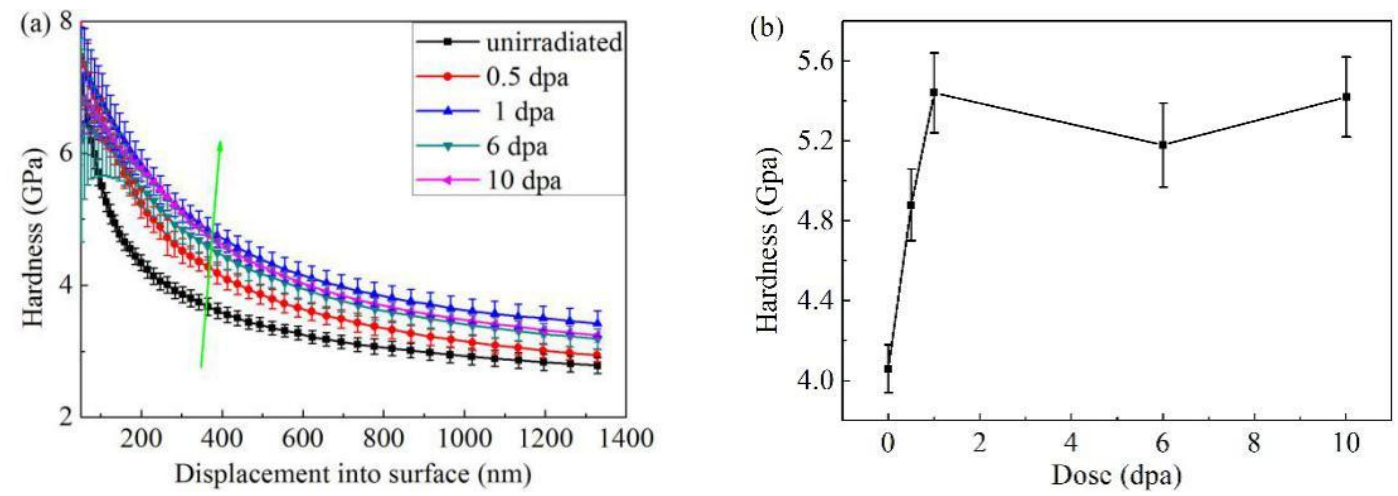

Fig. 3. (a) The average nanoindentation hardness versus the indentation depth, (b) the hardness of samples as a function of irradiation fluence at $250 \mathrm{~nm}$ contact depth before and after $7 \mathrm{MeV} \mathrm{Xe}$ ions irradiation.

Fig. 3(a) shows the hardening effects after irradiation, in which the hardness values of the irradiated samples are obviously higher than that of the unirradiated sample. Sammuels et al. [22] have reported that the hardness measured by the Berkovich diamond indenter tip is in the region extending to about seven times of the indenter's contact depth. In order to avoid the soft substrate effect, the average hardness values at $250 \mathrm{~nm}$ contact depth are used to investigate the irradiation-induced hardening effect. The hardness value of the original sample at 250 $\mathrm{nm}$ contact depth is about $4.06 \mathrm{GPa}$. For irradiated samples, the corresponding hardness values increase to $4.88,5.44,5.16$ and $5.42 \mathrm{GPa}$ at dose of $0.5,1,6$ and 10 dpa, respectively. Obviously, the hardness of irradiated samples increase significantly with irradiation dose from 0 to $1 \mathrm{dpa}$, then are almost no obvious change from 1 to 10 dpa. It suggests that the irradiation induced hardening mainly occurs at low irradiation dose ( $\leq 1 \mathrm{dpa})$ and approximately saturates with further increase of irradiation dose (1 10 dpa). 


\subsection{GIXRD Analysis of the Lattice Expansion of Irradiated samples}

Fig. 4(a) shows the GIXRD patterns of samples irradiated by Xe ions with irradiation dose from 0 to $27 \mathrm{dpa}$. One important phenomenon is diffraction peaks shifting to low 2-theta angle. Fig. 4(b) shows the results of zoomed $\gamma(111)$ peaks, and the $\gamma$ (111) peak positions are $43.77^{\circ}, 43.75^{\circ}, 43.72^{\circ}, 43.71^{\circ}$ and $43.68^{\circ}$ corresponding to irradiation dose of $0,1,6,10$ and $27 \mathrm{dpa}$. It is clear that the peak positions shift to low angle with increasing irradiation dose. The calculated lattice expands with increasing irradiation dose, and the lattice expansion ratios reaches up to $0.17 \%$ at the highest irradiation dose of $27 \mathrm{dpa}$, as shown in Fig. 4(c). The similar lattice expanding was also observed in $\mathrm{Ni}^{10+}$ ions irradiated Hastelloy $\mathrm{N}$ alloy [23]. The lattice expansion suggests that the defects are randomly distributed and their concentration is sufficient to influence the long range order, and M. Liu et al. [11] have investigated the irradiation induced microstructural evolution of Hastelloy $\mathrm{N}$ alloy, they found that radiation induced defects in Hastelloy $\mathrm{N}$ alloy are mainly small vacancy and interstitial clusters at irradiation dose below $1 \mathrm{dpa}$, resulting in the beginning of microstrain just like the present study. When irradiation dose exceeds 1 dpa, the defects grew up by absorbing the point defects, and finally evolved into the dislocation loops. So the lattice expansion of Hastelloy $\mathrm{N}$ alloy under ion irradiation may be attributed to the formation of irradiation-induced defects.
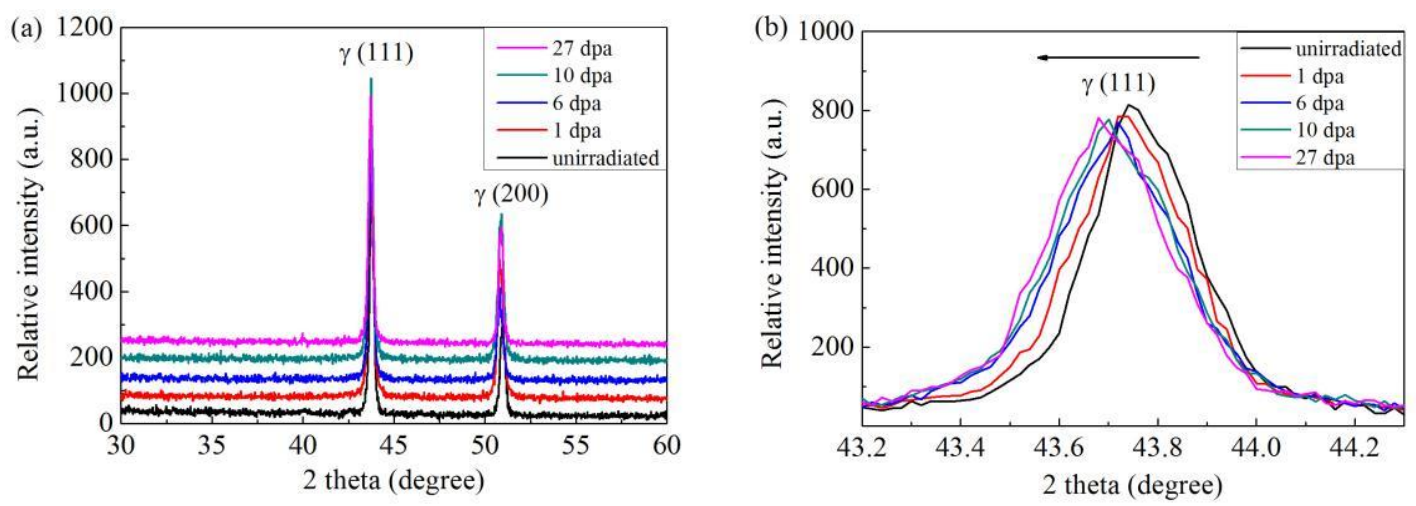


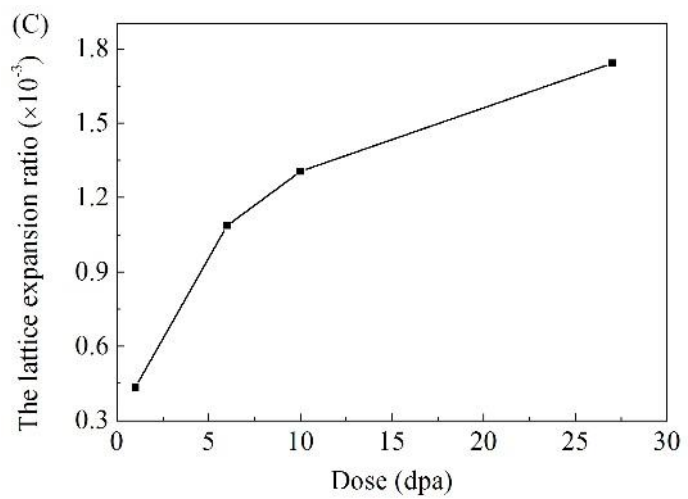

Fig. 4. (a) Normalized glancing incident X-ray diffraction patterns, (b) the enlarged peak of $\gamma$ (111), (c) the lattice expansion ratio as a function of different doses of samples before and after irradiation

\subsection{TEM results}

Fig. 5 shows the bright-field micrographs of the cross-sectional Hastelloy $\mathrm{N}$ alloy samples before and after irradiation. For the unirradiated sample, only some dislocations lines is observed, as shown in Fig. 5(a). Figs. 5(b) and (c) show that the irradiation induced damage layer thicknesses are approximately spread over 1600 and $400 \mathrm{~nm}$ for samples irradiated with $7 \mathrm{MeV}$ and $1 \mathrm{MeV}$ Xe ions, respectively. Which are slightly greater than SRIM calculation. Figs. 5(d-f) show the morphological evolution of defects in samples irradiated by $7 \mathrm{MeV}$ (1 and $10 \mathrm{dpa})$ and $1 \mathrm{MeV}$ (27 dpa) Xe ion, respectively. The regions with the highest defect density (peak damage area) were chosen for the comparison, and using the same diffraction condition with $\mathrm{g}$ $=[002]$. For the sample irradiated at a dose of $1 \mathrm{dpa}$, a large number black dot defects and a few of dislocation loops can be observed, as marked by the circles and squares in Figs. 5(d), respectively. The black dot defects have been identified either as small dislocation loops or stacking fault tetrahedra (SFT) [24-26] or solute clusters in some literatures [27,28]. For samples irradiated at higher doses of 10 and $27 \mathrm{dpa}$, many distinguishable dislocation loops with large size can be found, while there are still some black dot defects remaining in the matrix, as shown in Fig. 5(e) and (f). 
(a) unirradiated

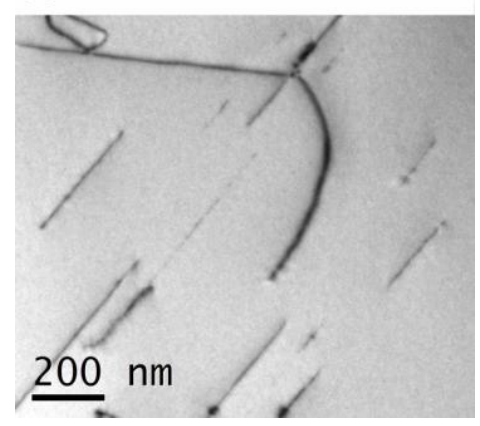

(d) $1 \mathrm{dpa}$

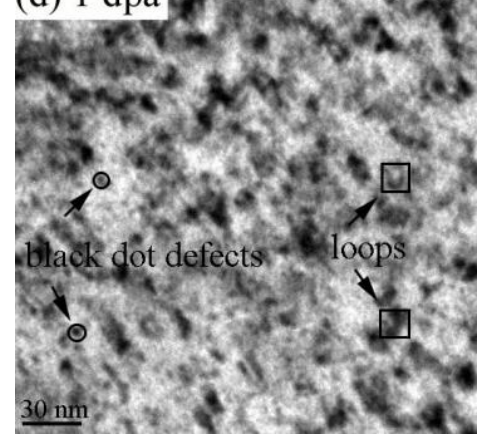

(b) $7 \mathrm{MeV}-10 \mathrm{dpa} \downarrow \downarrow \downarrow$ ions

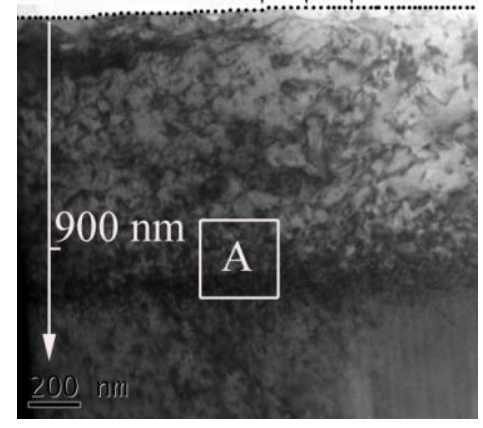

(c) $1 \mathrm{MeV}-27 \mathrm{dpa} \downarrow \downarrow$ ions
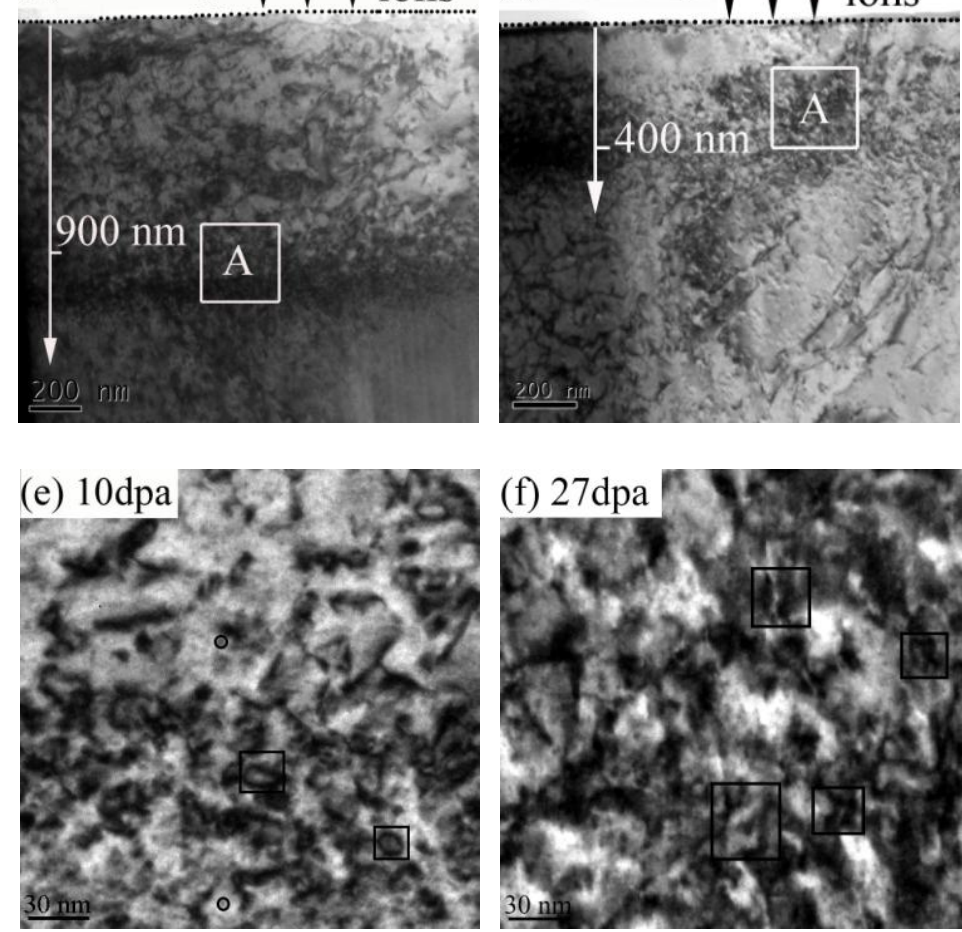

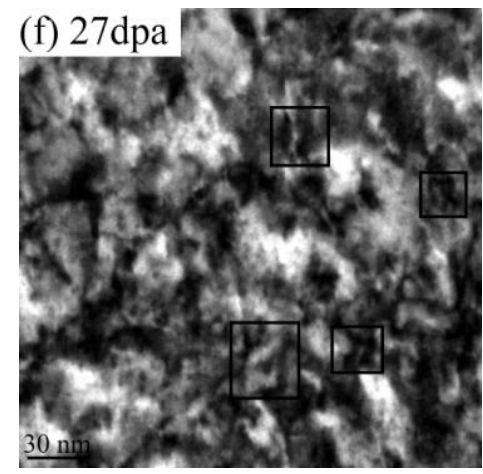

Fig. 5. Bright-field TEM images of Hastelloy $\mathrm{N}$ alloy: (a) before irradiation, (b) irradiated to a dose of $10 \mathrm{dpa}(7 \mathrm{MeV})$, (c) irradiated to a dose of $27 \mathrm{dpa}(1 \mathrm{MeV})$, "A" represents the peak damage area in (b) and (c). (d) The peak area of sample irradiated to a dose of $1 \mathrm{dpa}(7 \mathrm{MeV}), \mathrm{g}=$ [002]. (e) The peak area of sample irradiated to a dose of $10 \mathrm{dpa}(7 \mathrm{MeV}), \mathrm{g}=$ [002]. (f) The peak area of sample irradiated to a dose of $27 \mathrm{dpa}(1 \mathrm{MeV}), \mathrm{g}=$ [002]. Black dot defects and loops are marked by the circles and squares in (b), (c) and (d), respectively.

Fig. 6(a) shows the distribution of defects (including black dot defects and dislocation loops) sizes for samples irradiated at doses of 1, 10 and $27 \mathrm{dpa}$, and the corresponding average sizes of defects are $\sim 5,11$ and $19 \mathrm{~nm}$, respectively. H.C. Chen et al [29] observed that the black dot defects appeared in Hastelloy $\mathrm{N}$ using Xe ion irradiation at a dose of $0.33 \mathrm{dpa}$, and the average size of the defects was $\sim 2 \mathrm{~nm}$. It is obvious that the size of defects increases significantly with increasing irradiation dose.

Fig. 6(b) shows the number densities of defects of samples irradiated at different doses. For the black dot defects, the number density of them dramatically decreases from $5.8 \times 10^{22} \mathrm{~m}^{-3}$ to $6 \times 10^{21} \mathrm{~m}^{-3}$ with increasing irradiation dose from 1 to $27 \mathrm{dpa}$. For the dislocation loops, the number density of them initially increase from $1.1 \times$ $10^{22} \mathrm{~m}^{-3}$ to $3.7 \times 10^{22} \mathrm{~m}^{-3}$ with irradiation dose from 1 to $10 \mathrm{dpa}$, and then decrease to 
$2.4 \times 10^{22} \mathrm{~m}^{-3}$ with increasing irradiation dose to $27 \mathrm{dpa}$. And the total number densities of defects (including black dot defects and dislocation loops) decrease from $6.9 \times 10^{22} \mathrm{~m}^{-3}$ to $3.0 \times 10^{22} \mathrm{~m}^{-3}$ with irradiation dose from 1 to $27 \mathrm{dpa}$. C. Lu et al [24] also found that the dislocation loop size increases while the loop density decreases at the high fluences in both $\mathrm{Ni}$ and $\mathrm{Ni}-\mathrm{xFe}$ alloy after using $\mathrm{Au}$ ion irradiation at room temperature.
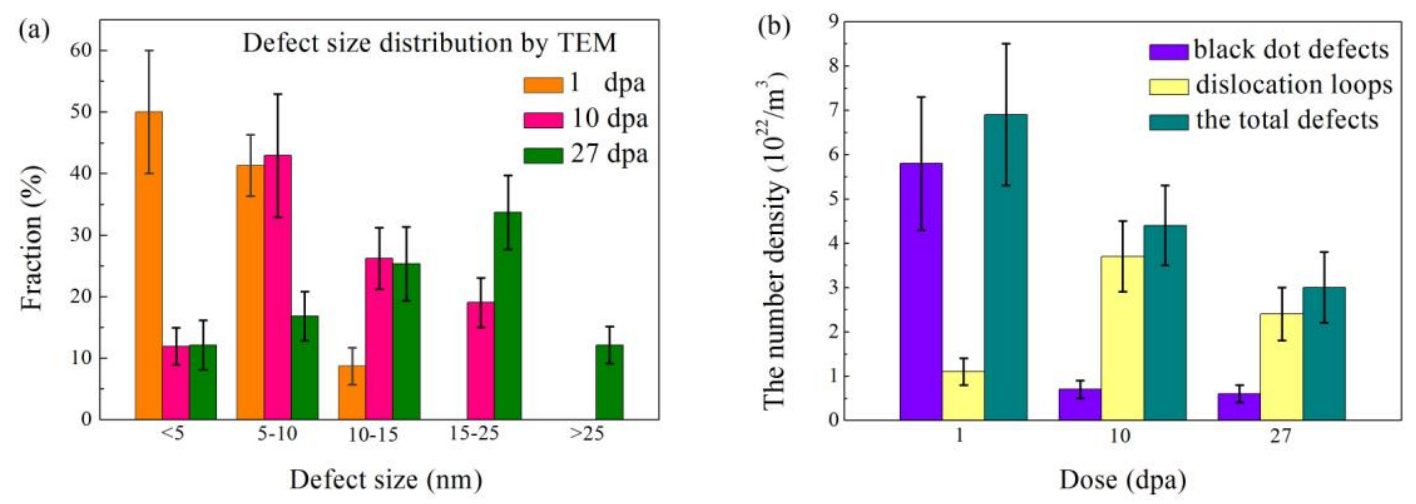

Fig. 6. (a) Defect size distribution and (b) defects number density in Hastelloy $\mathrm{N}$ after Xe ion irradiation with doses of 1, 10 and 27dpa, observed by TEM. The total defects in (b) include the black dot defects and dislocation loops.

\section{Discussion}

Usually, the microstructural evolution of irradiated metal and alloy consisted of three stages [5-12]. (i) At low ion irradiation dose ( $\leq 1 \mathrm{dpa})$, appearance of visible black dot defects, and the density of the black dot defects and their average size increase with ion dose. (ii) At intermediate ion irradiation dose ( $>1 \mathrm{dpa}$ ), the dislocation loops are formed and grow into larger loops. Meanwhile, the black dot defects are also evolved into bigger size, but their density greatly decreases. (iii) With increasing irradiation dose, the loop diameter increases and may coalesce with each other to form the dislocation networks. For Hastelloy $\mathrm{N}$ alloy, the incident high energetic Xe ions can introduce a large number of supersaturated vacancies and interstitials. And the diffusion and aggregation of the defects may cause the formation of the black dot defects in materials. The black dot defects are found to trap point defects and their size grew up by absorbing the point defects [30]. Moreover, the 
irradiation induced interstitial-type dislocation loops are preferentially nucleated and grow by absorbing the interstitial atoms [31,32]. The dislocation and dislocation loops were effective sink sites for the black dot defects [33]. Hence, the increase of the number density of dislocation loops is correlated with the decrease of the black dot defects.

It is worth to note that there is no void formation observed under TEM observation in the samples irradiated with different doses at RT, as shown in Fig. 5. For void nucleation, it is necessary to reach a critical vacancy concentration depending on the temperature and nucleation size of a void, according to the results of statistical thermodynamic analysis given in [34]. No observed void formation at this study may be attributed to the fact that the samples were irradiated at RT. In general, the temperature of irradiation-induced void formation is about $0.3-0.55 \mathrm{~T}_{\mathrm{m}}\left(\mathrm{T}_{\mathrm{m}}\right.$ is the melting point) [35-39], Since the $\mathrm{T}_{\mathrm{m}}$ of Hastelloy $\mathrm{N}$ alloy is about $1400{ }^{\circ} \mathrm{C}$, the void only can be formed at about $400-700{ }^{\circ} \mathrm{C}$. We propose one possible mechanism to explain the irradiation-induced volumetric swelling at RT. When alloys were irradiated by heavy ions, excess exotic ions were injected into the incompressible solid. This process produced a large number of vacancy and interstitial defects. Once the vacancy-type defect is formed, the interstitials expelled may contribute to excess volume, even there is no apparent void observed under TEM. This may lead to the volumetric swelling of irradiated alloys. The discrepancy between the volumetric swelling and the lattice expanding indicates that the irradiation induced defects contribute much more volumetric swelling than lattice expanding. This may be caused by sputtering leading more volumetric swelling than lattice. The ion beam energy is intermediate $\mathrm{MeV}$ level, and may induce volcano shape sputtering [40].

The black dot defects and small dislocation loops appeared at low dose $(<1 \mathrm{dpa}$ may explain the initial hardening. The irradiation induced those defects can act as obstacles to inhibit the free movement of dislocation lines, thus lead to the hardening $[41,42]$. And the contribution of defects to the hardening can be estimated using the 
Orowan equation [43]:

$$
\Delta \sigma=\alpha \cdot M \cdot G \quad b \sqrt{N}
$$

Where $\alpha$ is the obstacle strength, varied from 0 to 1 , which strongly depends on the type of defect. $M$ is the Taylor factor, $G$ is the shear modulus and $b$ is the module of the Burgers vector. For a given material, these three parameters are constants. $N$ and $d$ are the defect number densities and their average size, respectively. $\Delta \sigma$ is the change in yield stress, which is proportional to the square root of $N$ and $d$. Taking into account that the hardness is proportional to the yield stress of materials. It is clear that the change in hardness is also proportional to the square root of $N$ and $d$. In this study, for the irradiated Hastelloy $\mathrm{N}$, the size and the number density of defects have obviously increased from 0 to $1 \mathrm{dpa}$. And the measured hardness values of irradiated samples increase significantly with increasing irradiation dose from 0 to $1 \mathrm{dpa}$. Based on the Orowan equation, it is reasonable that the increase of the size and density of defects lead to the hardening. Moreover, although the average size of the defects continued to increase from 1 to $10 \mathrm{dpa}$, the total number density decreases. Thus the combined effect of the two factors may cause the saturation of the hardness of irradiated samples.

\section{Summary}

Ion irradiation-induced swelling and hardening in Hastelloy $\mathrm{N}$ alloy have been investigated under Xe ions irradiation.

1. The volumetric swelling increases with increasing irradiation dose. Moreover, no saturation is observed at $27 \mathrm{dpa}$.

2. The irradiation induced hardening initiates at low ion dose $(\leq 1 \mathrm{dpa})$ then saturates with higher ion dose $(1 \sim 10 \mathrm{dpa})$.

3. The irradiation induced lattice expansion is observed. The lattice expansion ratio increases with ion dose, and reaches up to $0.17 \%$ at $27 \mathrm{dpa}$.

4. The irradiation induced defects, including the black dot defects, dislocation 
loops have been observed. With increasing irradiation dose from $1 \mathrm{dpa}$ to $27 \mathrm{dpa}$, the average size of the defects increases from $5 \mathrm{~nm}$ to $19 \mathrm{~nm}$ but their total density decreases from $6.9 \times 10^{22} \mathrm{~m}^{-3}$ to $3.0 \times 10^{22} \mathrm{~m}^{-3}$.

5. The irradiation induced volumetric swelling could be ascribed to excess volume of irradiation induced defects. The pinning effect is used to explain irradiation-induced hardening, where the irradiation induced defects can act as obstacles for the free movement of dislocation lines, and the evolution of the defects' size and number density could be responsible for the saturation of hardness.

\section{Acknowledgements}

This work is supported by the strategic priority research program of Thorium-based Molten-Salt Reactor (TMSR) and China-Australia Joint Research Program (Grant No 2014DFG60230). The authors are grateful to the institute of modern physics, Chinese academy of science (IMP-CAS) for providing the platform for ion irradiation experiments.

\section{References}

[1]M.W. Rosenthal, P.N. Haubenreich, R.B. Briggs, The development status of molten-salt breeder reactors. ORNL-4812 (1972) 195-218.

[2]L. Mathieu, D. Heuer, R. Brissot, C. Garzenne, C.L. Brun, D. Lecarpentier, E.Liatard, J. Loiseaux, O. Meplan, E. Merle-Lucotte, A. Nuttin, E. Walle, J. Wilson, Prog. Nucl. Ener. 48 (2006) 664-679.

[3]L.C. Olson, J.W. Ambrosek, K. Sridharan, M.H. Anderson, T.R. Allen, J. Fluorine. Chem. 130 (2009) 67-73.

[4]Preliminary Fluoride Salt-Cooled High Temperature Reactor (FHR) Materials and Components White Paper, UCBTH-12-003, August (2012).

[5]S.X. Jin, L.P. Guo, Z. Yang, D.J. Fu, C.S. Liu, W. Xiao, R. Tang, F.H. Liu, Y.X. Qiao, Nucl. Instrum. Methods Phys. Res. Sect. B 269 (2011) 209-215.

[6]H.K. Zhang, Z.W. Yao, C. Judge, M. Griffiths, J. Nucl. Mater. 443 (2013) 49-58. 
[7]H.F. Huang, J.J. Li, D.H. Li, R.D. Liu, G.H. Lei, Q. Huang, L. Yan J. Nucl. Mater. 454 (2014) 168-172.

[8]E. Getto, Z. Jiao, A.M. Monterrosa, K. Sun, G.S. Was, J. Nucl. Mater. 465 (2015) 116-126.

[9]K. Jin, H. Bei, Y. Zhang, J. Nucl. Mater. 471 (2016) 193-199.

[10]M. Desormeaux, B. Rouxel, A.T. Motta, M. Kirk, C. Bisor, Y. de Carlan, A. Legris, J. Nucl. Mater. 475 (2016) 156-167.

[11] M. Liu, Y.L. Lu, R.D. Liu, X.T. Zhou, Microsc. Res. Tech. 77 (2014) 161-169.

[12]K. Liu, J. Lin, L.M. Bao, H.X. Xu, L. Xu, Z. Liu, J.R. Zeng, S.L. Long, L.L. Cao, J.J. Li, L.Yan, X.L. Li, G.L. Zhang, Y. Li, J. Nucl. Sci. Technol. 52 (2015) 829-836.

[13]P. Guo, J.M. Xue, L. Yan, Q. Huang, Z.J. Li, P. Huai, X.T. Zhou, Acta Metall. Sin. (Engl. Lett.), 28 (2015) 903-908.

[14]S.Y. Liu, G.Y. Xu, Y.W. Zhang, X. Wang, M.X. Tang, Z.Q. Zhao, B.C. Wei, Acta Scientiarum Naturalium Universitatis Pekinensis. 51 (2015) 783-790.

[15]X. Ma, H.P. Liu, L.T. Sun, M.T. Song, X.L. Zhu, S. Sha, W.T. Feng, D.C. Zhang, S.F. Zhang, B. Li, J.Y. Li, D.B. Qian, S.Y. Xu, D.Q. Gao, P.Z. Wang, L.Z. Ma, K.D. Man, G.Q. Xiao, H.W. Zhao, W.L. Zhan, J. Phys.: Conf. Ser. 163(2009) 012104.

[16]J.F. Ziegler, M.D. Ziegler, J.P. Biersack, Nucl. Instrum. Methods Phys. Res. Sect. B 268 (2010) 1818-1823.

[17]R.E. Stoller, M.B. Toloczko, G.S. Was, A.G. Certain, S. Dwaraknath, F.A. Garner, Nucl. Instrum. Methods Phys. Res. Sect. B 310 (2013) 75-80.

[18]W.C. Oliver, G.M. Pharr, J. Mater. Res. 7 (1992) 1564-1583.

[19]K. Jin, C. Lu, L.M. Wang, J. Qu, W.J. Weber, Y. Zhang, H. Bei, Scripta Mater. 119 (2016) 65-70.

[20] E.H. Lee, Y. Lee, W.C. Oliver, L.K. Mansur, J. Mater. Res. 8 (1993) 377-387.

[21]W.D. Nix, H. Gao, J. Mech. Phys. Solids. 46 (1998) 411-425. 
[22]L.E. Sammuels, T.O. Mulhearn, J. Mech. Phys. Solids. 5 (1957) 125-134.

[23]H.F. Huang, J.J. Li, G.H. Lei, R.D. Liu, D.H. Li, Q. Huang, L. Yan, Mater. Rev. 8 (2014) 1-3.

[24]C. Lu, K. Jin, L.K. Beland, F. Zhang, T. Yang, L. Qiao, Y. Zhang, H. Bei, H.M. Christen, R.E. Stoller, L. Wang, Sci. Rep. 6 (2016) 19994

[25]B.H. Sencer, G.M. Bond, F.A. Garner, M.L. Hamilton, B.M. Oliver, L.E. Thomas, S.A. Maloy, W.F. Sommer, M.R. James, P.D. Ferguson, J. Nucl. Mater. 283 (2000) 324-328.

[26]B.H. Sencer, G.M. Bond, F.A. Garner, M.L. Hamilton, S.A. Maloy, W.F. Sommer, J. Nucl. Mater. 296 (2001) 145-154.

[27]A. Etienne, B. Radiguet, N.J. Cunningham, G.R. Odette, P. Pareige, J. Nucl. Mater. 406 (2010) 244-250

[28]H.F. Huang, D.H. Li, J.J. Li, R.D. Liu, G.H. Lei, S.X. He, Q. Huang, L. Yan, Mater. Trans. 55 (2014) 1243-1247.

[29]H.C. Chen, D.H. Li, R.D. Liu, H.F. Huang, J.J. Li, G. H Lei, Q. Huang, L.M. Bao, L. Yan, X.T. Zhou, Z.Y. Zhu, Nucl. Instrum. Methods Phys. Res. Sect. B 377 (2016) 94-98.

[30] A.F. Rowcliffe, L.K. Mansur, D.T. Hoelzer, R.K. Nanstad, J. Nucl. Mater. 391 (2009) 341-352.

[31]D.S. Bae, S.H. Nahm, H.M. Lee, H. Kinoshita, T. Shibayama, H. Takahashi, J. Nucl. Mater. 329 (2004) 1038-1042.

[32]M. Kiritani, H. Takata, K. Moriyama, F.E. Fujita, Philos. Mag. A. 40 (1979) $779-802$

[33]D.S. Bae, H. Kinoshita, H. Takahashi, J. Nucl. Mater. 302 (2002) 60-65.

[34] A.V. Kozlov, I.A. Portnykh, A E.A. Kinev, S.V. Bryushkova, International Symposium on Irradiation Effect on Materials ASTM-20, 2000.

[35] S.X. Jin, X.F. He, T.C Li, S.L. M, R.Tang, L.P. Guo, Mater. Charact. 72 (2012) $8-14$. 
[36] J.F. Bates, R.W. Powell, J. Nucl. Mater. 102 (1981) 200-213.

[37] J.F. Stubbins, F.A. Garner, J. Nucl. Mater. 191-194 (1992) 1295-1299.

[38] N.I. Budylkin, E.G. Mironova, V.M. Chernov, V.A. Krasnoselov, S.I. Porollo, F.A.Garner, J. Nucl. Mater. 375 (2008) 359-364.

[39] S.I. Porollo, A.M. Dvoriashin, Y.V. Konobeev, F.A. Garner, J. Nucl. Mater. 442 (2013) 809-812.

[40]Y.N. Cheblukov, A.Y. Didyk, A. Hofman, V.K. Semina, W Starosta, NUKLEONIKA. 49 (2004) 15-21

[41]S.J. Zinkle, G.S. Was, Acta. Mater. 61 (2013) 735-758.

[42] M.M. Choneim, F.H. Hammad, Int. J. Press. Ves. Pip. 74 (1997) 189-198.

[43] M. Lanbrecht, E. Meslin, L. Malerba, M. Hernandez-Mayoral, F. Bergner, P.Pareige, B. Radiguet, A. Almazouzi, J. Nucl. Mater. 406 (2010) 84-89. 